\title{
Significance of non-stationary characteristics of ground-motion on structural damage: shaking table study
}

\author{
Mohammad M. Kashani ${ }^{1}$ D $\cdot$ Xiao Ge $^{2} \cdot$ Matthew S. Dietz $^{2} \cdot$ Adam J. Crewe $^{2}$. \\ Nicholas A. Alexander ${ }^{2}$
}

Received: 29 September 2018 / Accepted: 11 June 2019 / Published online: 13 June 2019

(c) The Author(s) 2019

\begin{abstract}
This paper reports the results of a set of benchmark medium-scale shaking table tests to investigate the significance of the non-stationary characteristics of ground-motion on nonlinear dynamic responses and the structural damage of reinforced concrete (RC) columns. To examine the influence of ground-motion characteristics, four RC columns are tested under (1) near-field without pulse, (2) near-field pulse-like, and (3) far-field groundmotions. These ground-motion records were spectrally matched by the reweighted Volterra series algorithm without changing non-ergodic characteristics. To explore the confinement effects, two sets of column specimens are designed to represent the modern well-confined and older lightly-confined RC columns. Each column is tested in slight, extensive and complete damage limit states. Then aftershock excitations are conducted to investigate the performance of severely damaged RC columns. Low amplitude white-noise tests are conducted on pristine columns and after each damage limit state experiment to detect natural frequency variant of damaged columns using transfer function estimate. Furthermore, using time-frequency analysis, the real-time variant frequency of test specimens is estimated. The significant duration of ground-motions accounting for the effect of nonstationary characteristics of ground-motion is also estimated by time-cumulative damage analysis of the test results. Finally, the time-variant stiffness degradation of RC columns is estimated.
\end{abstract}

Keywords Shaking table $\cdot$ Ground-motion duration · Low-cycle fatigue · Time-frequency analysis · Transfer function estimate $\cdot$ Inelastic buckling

Mohammad M. Kashani

mehdi.kashani@soton.ac.uk

1 Faculty of Engineering and Physical Sciences, University of Southampton, Southampton SO17 1BJ, UK

2 Department of Civil Engineering, University of Bristol, Bristol BS8 1TR, UK 


\section{Introduction}

In performance-based design of reinforced concrete (RC) structures, ground columns in building structures, and piers in bridge structures are usually the most vulnerable components. In bridges, the seismic performance of the whole structure is governed by the performance of the piers when they are subjected to large earthquakes. This is because the current modern seismic design codes (CEN 2010; Caltrans 2013) rely on a proper detailing of the plastic hinge regions where most of the inelastic deformations are expected to occur. Hence, the structural performance is greatly influenced by the structural details (e.g. sufficient confinement for concrete) and material performance (e.g. ductility of reinforcing steel) (Mander et al. 1988; Chang and Mander 1994; Kunnath et al. 1997; Lehman 2000). Furthermore, ground-motion characteristics (frequency content, amplitude, duration etc.) have a significant effect on the nonlinear seismic response and cumulative damage of RC columns (Hancock and Bommer 2005, 2007; Chandramohan et al. 2016; Kashani et al. 2017a). Therefore, several researchers have developed numerical analysis methods to study the behaviour of RC components with different detailing when subjected to different types of ground-motions (Domizio et al. 2017; Kashani et al. 2017a; Nojavan et al. 2017; Su et al. 2017). Other researchers (Kunnath et al. 1997; Laplace et al. 1999; Lehman 2000; Elwood 2004; Johnson et al. 2006; Chen et al. 2008; Phan et al. 2007; Carrea 2010; Brown and Saiidi 2011) conducted several experimental studies on the impact of load history on structural damage of RC columns using quasi-static cyclic and dynamic shaking table tests.

Furthermore, quantifying the influence of a particular ground-motion time-series, on the nonlinear structural response and cumulative damage, by a few salient parameters is a challenging problem. Several researchers (Kramer 1996; Cornell 1997; Iervolino et al. 2006; Hancock and Bommer 2007; Raghunandan and Liel 2013; Sarieddine and Lin 2013) have employed a range of parameters (amplitude, energy, averaged frequency content, duration and envelope shape measures etc.) to investigate the most significant factors that govern the nonlinear dynamic response. Notably, it is apparent that there are differences in near/far field, with/without pulses, time-series. The differences between these ground-motions are typically expressed in terms of their power spectral content, which is statistically stationary (time-invariant) (Chatfield 2003). However, there are also differences in ground-motion time-series caused by the non-stationary (time-variant) statistical characteristics, which are not captured by power spectral alone (Han et al. 2017). These, non-stationary statistical characteristics (Chatfield 2003), include the envelope shape and the presence of large, time localised, pulses in the ground-motion time-series.

Moreover, the effect of ground-motion duration has been widely studied, but resulted in mixed findings, suggesting that the effect of ground-motion duration depends on system response measure (i.e. damage measures). Hancock and Bommer (2006) reported that comparing the responses to spectrally compatible long and short duration ground-motions may not yield significant differences in the maximum peak displacement response. However, long-duration ground-motions will affect the accumulated damage on the structure due to low-cycle high-amplitude fatigue degradation of materials (Hancock and Bommer 2007). Furthermore, several duration metrics have been suggested by various researchers for assessing nonlinear structural response (Bommer and Martinez-Pereira 2000; Kempton and Stewart 2006; Foschaar et al. 2012). A recent study conducted by Chandramohan et al. (2016), proposes a methodology to quantify the effect of ground-motion duration on the probability of structural collapse. They concluded that the probability of structural collapse is larger under a long-duration ground-motion than a spectrally equivalent short-duration 
ground-motion. Their finding is in contrast to most other previous studies (Hancock and Bommer 2006) which concluded that ground-motion duration does not influence peak structural deformations. These mixed conclusions are mainly due to limitations in numerical models (low-order nonlinear spring models, fibre models, 3D continuum models), and not separating out the effects of stationary and non-stationary characteristics of the ground-motions.

More recently, Kashani et al. (2017a) developed a novel numerical approach to quantify the impact of ground-motion types (near/far field, with/without pulses time-series), caused by the non-stationary content (time-varying parameters that are not captured by power spectral content alone), on the nonlinear dynamic response of RC bridge piers, including the effect of material cyclic degradation. They used the new algorithm (known as RVSA) developed by Alexander et al. (2014) to generate a set of artificial spectrally equivalent ground-motions. They used the suggested far-field (FF), near-field without pulse (NFWP) and near-field pulse-like (NFPL) ground-motions in FEMA P695 (2009). The selected ground-motions were different in their stationary and non-stationary components. Using the RVSA, they matched these ground-motions to a target response spectrum (without qualitatively changing the non-stationary ground-motion characteristics, i.e. envelope and pulses) to be used in nonlinear dynamic analyses. With this approach, they isolated the influence of ground-motion envelope and pulses (non-stationary effects) from groundmotion response spectral characteristics (stationary effects). The structural model that they used was developed in earlier research by Kashani (2014), Kashani et al. (2015a, b, 2016) that account for the inelastic buckling and low-cycle fatigue degradation of longitudinal reinforcing bars, concrete cover spalling and core concrete crushing. They concluded that the non-stationary content of ground-motion affects the cumulative damage of structural response and has less significant impact on peak displacement response. However, their conclusions are purely based on a numerical exploration study and have not been verified experimentally. Accordingly, the aim of this paper is to extend the earlier work by Kashani et al. (2017a) and justify the numerical results through a comprehensive experimental shaking table study.

To this end, three medium scale well-confined columns and a lightly-confined RC column are cast. The well-confined columns represent the modern seismically designed $\mathrm{RC}$ columns and the lightly-confined column represents older RC columns. Three spectrally matched ground-motions including a NFWP, a NFPL, and a FF ground-motions are selected from the same set of ground-motions that used in numerical analysis conducted by Kashani et al. (2017a) for the shake table experiments. The three well-confined columns are tested under the selected ground-motions at different intensity, and the lightly-confined column is tested under FF ground-motion to investigate the influence of the reinforcement detail. Each column is tested in slight (scale factor $(\mathrm{SF})=0.25$, i.e. $25 \%$ ), extensive $(\mathrm{SF}=300 \%)$ and complete damage $(\mathrm{SF}=500 \%)$ limit states. After the complete damage limit state experiments, aftershock excitations (the same ground-motion as the mainshock, $\mathrm{SF}=300 \%$ ) are conducted to investigate the performance of severely damaged RC columns. Low amplitude white-noise tests are conducted on pristine columns and after each damage limit state experiments to detect the change in natural frequency content of the damaged columns using transfer function estimate. Furthermore, using a novel time-frequency analysis technique, the real-time variation in specimen's response frequency, during tests, is estimated. The significant duration of the ground-motions accounting for the effect of non-stationary characteristics of the ground-motion is estimated by an innovative timecumulative damage analysis of experimental results and compared with previous numerical studies. Finally, the time-varying stiffness degradation of RC columns is estimated, and 
the influence of non-stationary characteristics of the ground-motions on peak displacement response of RC columns is studied.

\section{Experimental programme}

\subsection{Specimen details and preparation}

Three rectangular well-confined RC columns are designed to represent the typical modern seismically designed columns according to EC2 (CEN 2008), and EC8 (CEN 2010). A further lightly-confined column is designed to represent older RC columns. All columns are $250 \times 250 \mathrm{~mm}$ in cross sections and $2300 \mathrm{~mm}$ in height. The well-confined columns include 8 number of $16 \mathrm{~mm}$ vertical reinforcement with $8 \mathrm{~mm}$ horizontal tie/ link reinforcement at $80 \mathrm{~mm}$ spacing, and lightly-confined column includes 8 number of $16 \mathrm{~mm}$ vertical reinforcement with $8 \mathrm{~mm}$ horizontal tie/link reinforcement at $200 \mathrm{~mm}$ spacing (Fig. 1). Three compressive tests of concrete cylinders are conducted, which indicated the average concrete strength is $40 \mathrm{MPa}$. The reinforcing steel used in these columns are typical B500 British manufactured reinforcing steel (2005) with a nominal yield strength of $500 \mathrm{MPa}$. Three tension tests are conducted to characterise the mechanical properties of the reinforcing steel (vertical and tie reinforcement). The mechanical properties of the reinforcement used in the RC columns are summarised in Table 1.

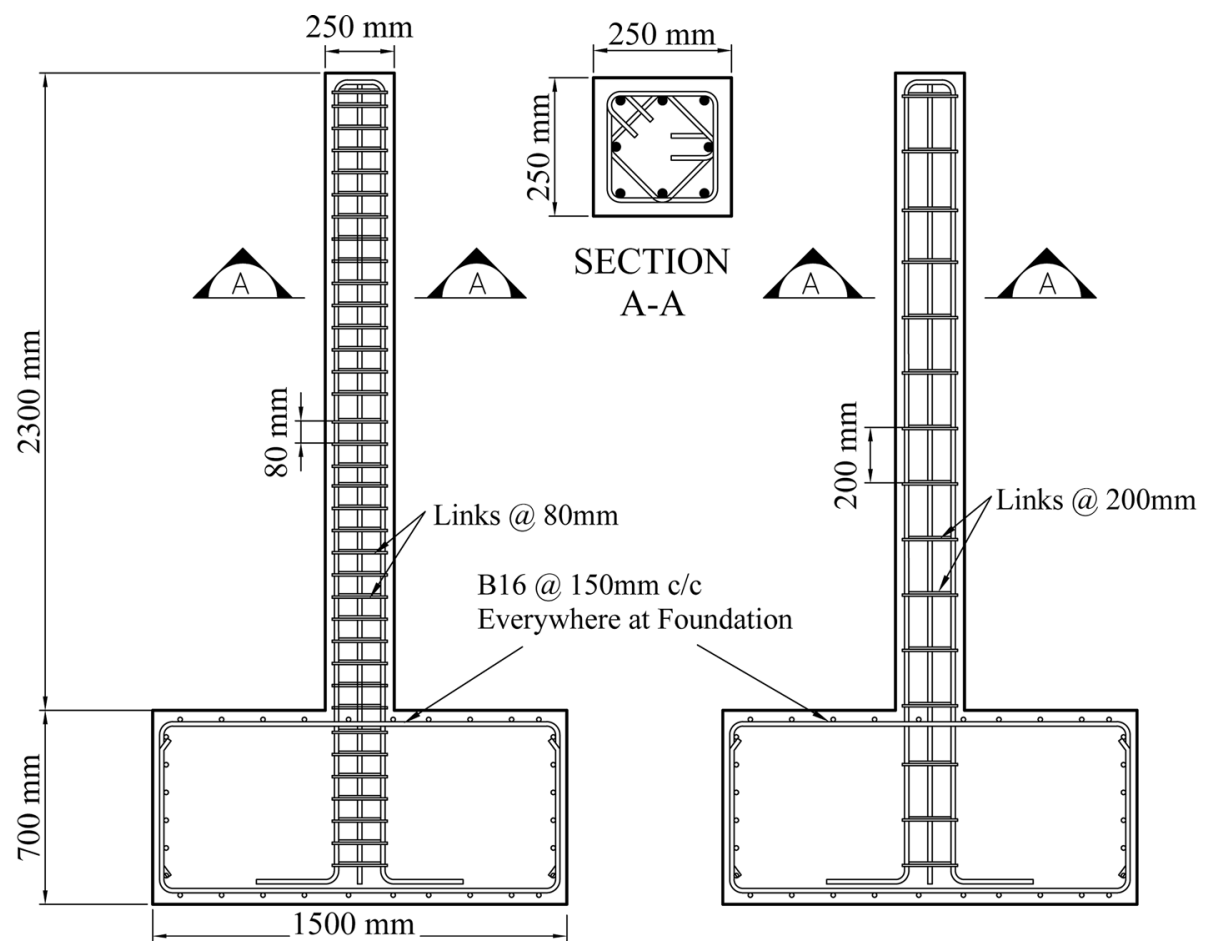

Fig. 1 Details of test specimens 
Table 1 Mechanical properties of tests specimens

\begin{tabular}{llll}
\hline Bar diameter $(D)$ & & $8 \mathrm{~mm}$ & $16 \mathrm{~mm}$ \\
\hline Yield strain & $\varepsilon_{y}$ & 0.00261 & 0.002733 \\
Yield stress (MPa) & $\sigma_{y}$ & 520 & 530 \\
Elastic modulus (MPa) & $E_{s}$ & 200426 & 193913 \\
Hardening strain & $\varepsilon_{s h}$ & N/A & 0.02547 \\
Strain at maximum stress & $\varepsilon_{u}$ & 0.05660 & 0.164800 \\
Maximum stress (MPa) & $\sigma_{u}$ & 645 & 640 \\
Fracture strain & $\varepsilon_{r}$ & 0.151800 & 0.227350 \\
\hline
\end{tabular}

Three further compressive and cyclic tests on the reinforcing bars are conducted to characterise the inelastic buckling and cyclic behaviour of the bar with different slenderness ratios; i.e. $L / D=5$ and 12.5 , where $L$ is the length of the bar between ties and $D$ is the diameter of vertical bars. Figure $2 b$, d shows the influence of tie spacing on inelastic buckling behaviour of reinforcement bars. It should be noted that the strain in Fig. 2b, $\mathrm{c}$ is the average strain over the buckling length, and hence, it is shown as 'Mean Strain' in the figure. The detailed discussion of the experimental testing and strain measurement is available in Kashani et al. (2013). The inelastic buckling of the vertical bars is an important parameter that affects the nonlinear behaviour of RC columns in flexure (Kashani 2014; Kashani et al. 2015a, b, 2016; Salami et al. 2019).

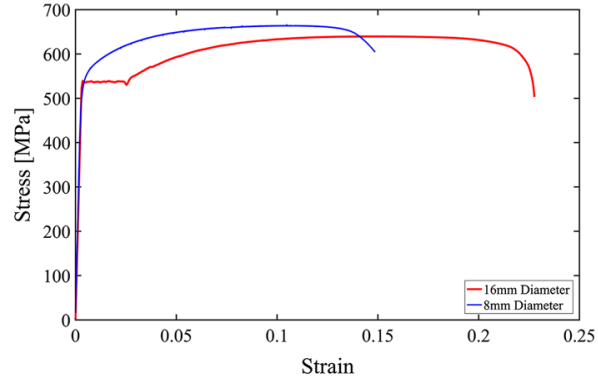

(a)

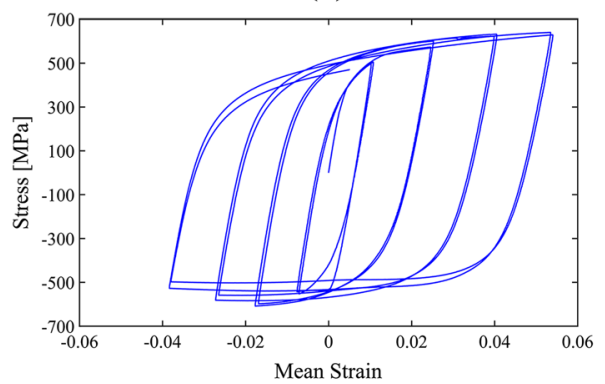

(c)

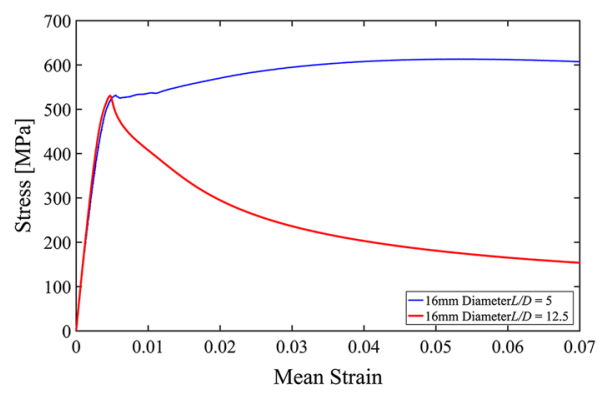

(b)

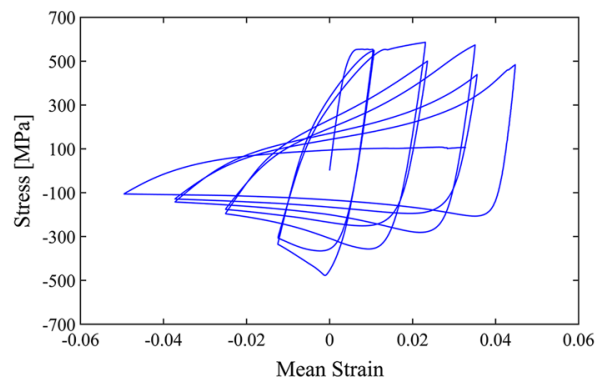

(d)

Fig. 2 Stress-strain behaviour of reinforcing steel material used in RC columns specimens: a tension test, b compression test, $\mathbf{c}$ cyclic test with $L / D=5$, and d cyclic test with $L / D=12.5$ 


\subsection{Experimental test setup}

A safety steel frame is fixed by bolts to a $3 \times 3 \mathrm{~m}, 6$ degrees of freedom shaking table, and the RC column specimen is located in the centre (Fig. 3). To generate the inertia force in the experiments a 3-tonne mass block is attached to the top of the column. To select the appropriate mass and ground-motion scale, we conducted preliminary nonlinear timehistory analyses on the proposed columns. The analysis results showed that the 3-tonne mass is within the capacity of shake table and can generate reasonable structural damage in the columns. To provide a fixed connection between the column's foundation and the shake table, four channel sections are used at four sides of the foundation. This provides full restraint, in all directions, at the base of the column foundation. To fix the mass block on top of the column, a demountable steel frame is built on top of the column that allows the mass to sit on the column head rigidly. A global coordinate system is introduced for the experiments. In this system $x$ is the horizontal plane of shaking direction, $y$ is the out of horizontal plane direction and $z$ is vertical coordinate.

Six accelerometers are used to monitor the performance of shaking table in all 6 degrees of freedom. An accelerometer is placed on the top of the column to record the response in shaking $x$ direction. Two accelerometers are placed on the mass block to record the responses in $x$ and $y$ directions. An accelerometer is also placed on top of the foundation to record the exact input ground-motion to the RC column, and compare it to the recorded ground-motion on the shake table. The detailed layout of the instrumentations is shown in

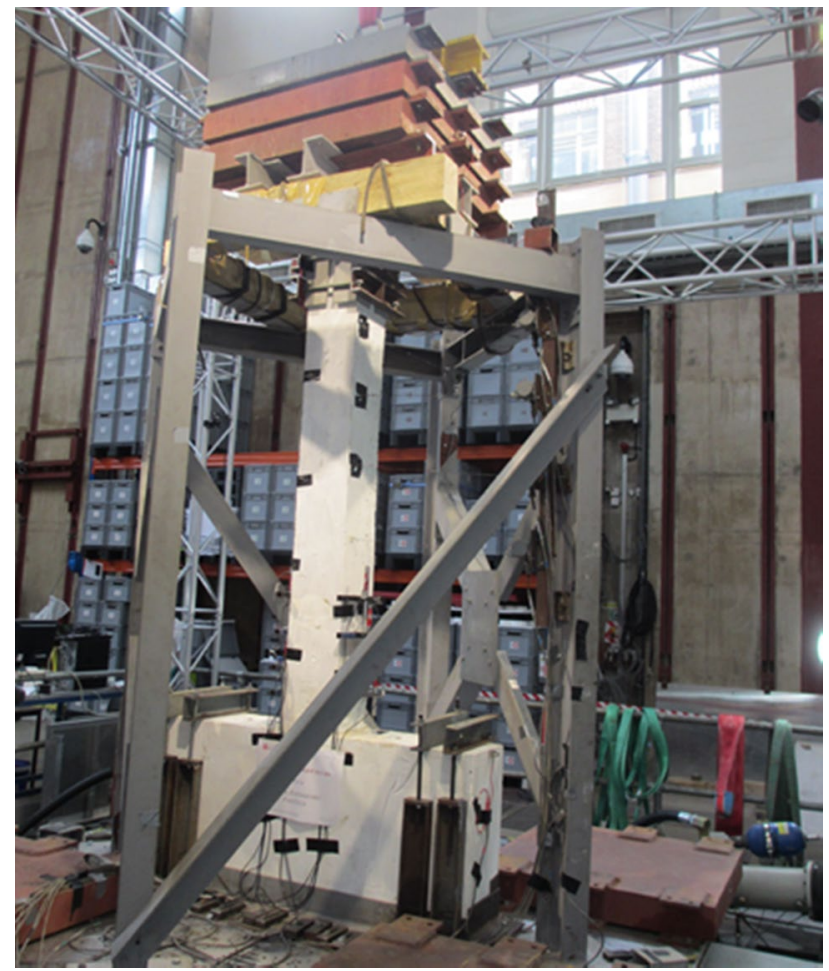

Fig. 3 Shaking table experimental test setup 
Fig. 4. Eight Linear Voltage Displacement Transducers (LVDT) are placed on front and back of the columns' base to measure the columns' curvature and slippage of the columns' base.

Four cable extension position transducers (Celesco) are used along the height of the columns to measure the lateral displacement of the columns in the $x$ direction. An additional Celesco is used to measure the lateral displacement of the columns in the $y$ direction.

\subsection{Ground-motion selection and matching}

As explained in the introduction, the purpose of this experiment is to investigate the impact of non-stationary characteristics of the ground-motion and reinforcement detail on the structural damage of RC columns. To this end, three ground-motions are selected that include a Far-Field (FF), a Near-Field without Pulse (NFWP), and a Near-Field Pulse-Like (NFPL) ground-motions.

A number of ground-motion records with different properties are listed in FEMA P695 (2009). For this study, Northridge and Imperial Valley ground-motions are selected for NFWP and NFPL experiments respectively, and Manjil ground-motion is selected for FF experiments.

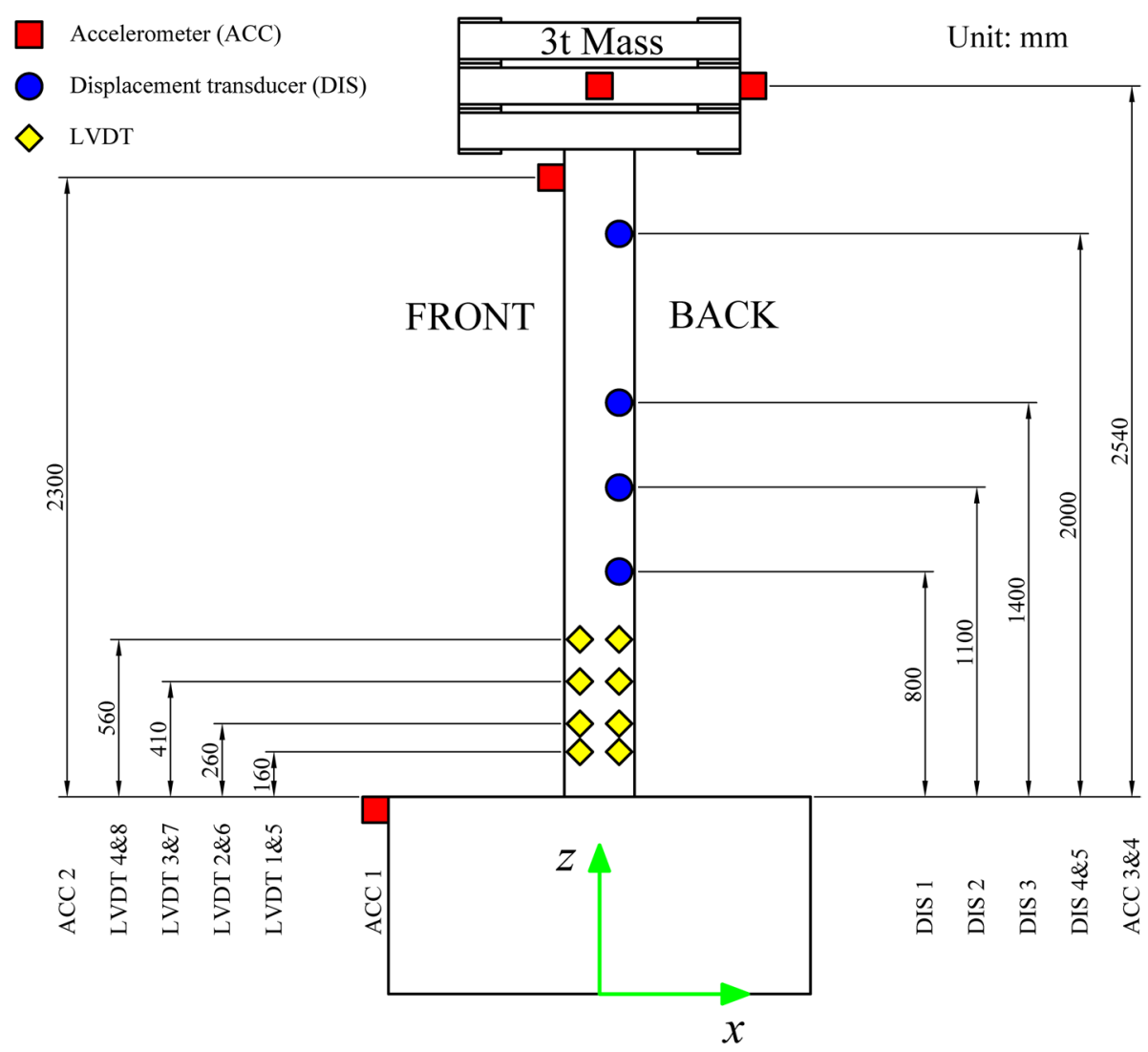

Fig. 4 Layout of specimen instrumentation 
In order to separate out the stationary and non-stationary characteristics of groundmotions, all of the ground-motions are matched to the mean response spectrum of FF ground-motions in FEMA P695 (2009) using the Reweighted Volterra Series Algorithm (RVSA) (Alexander et al. 2014), which has been successfully used in a numerical exploration study by Kashani et al. (2017a). In this study, we are using the same spectrally matched ground-motions that were used in the numerical study (Kashani et al. 2017a). Figure $4 \mathrm{a}$ shows the target and matched response spectra of selected ground-motions, and Fig. 5b shows the corresponding matched ground-motion time-series that used in

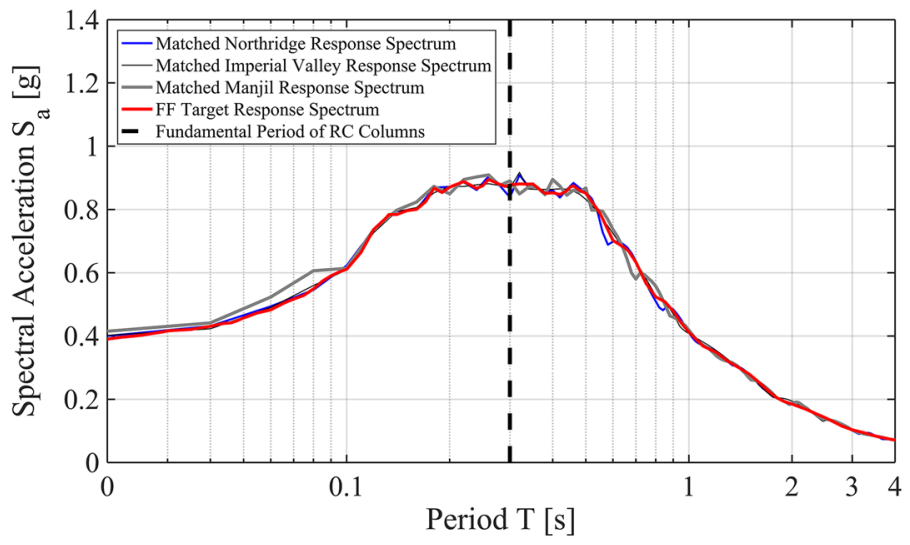

(a)
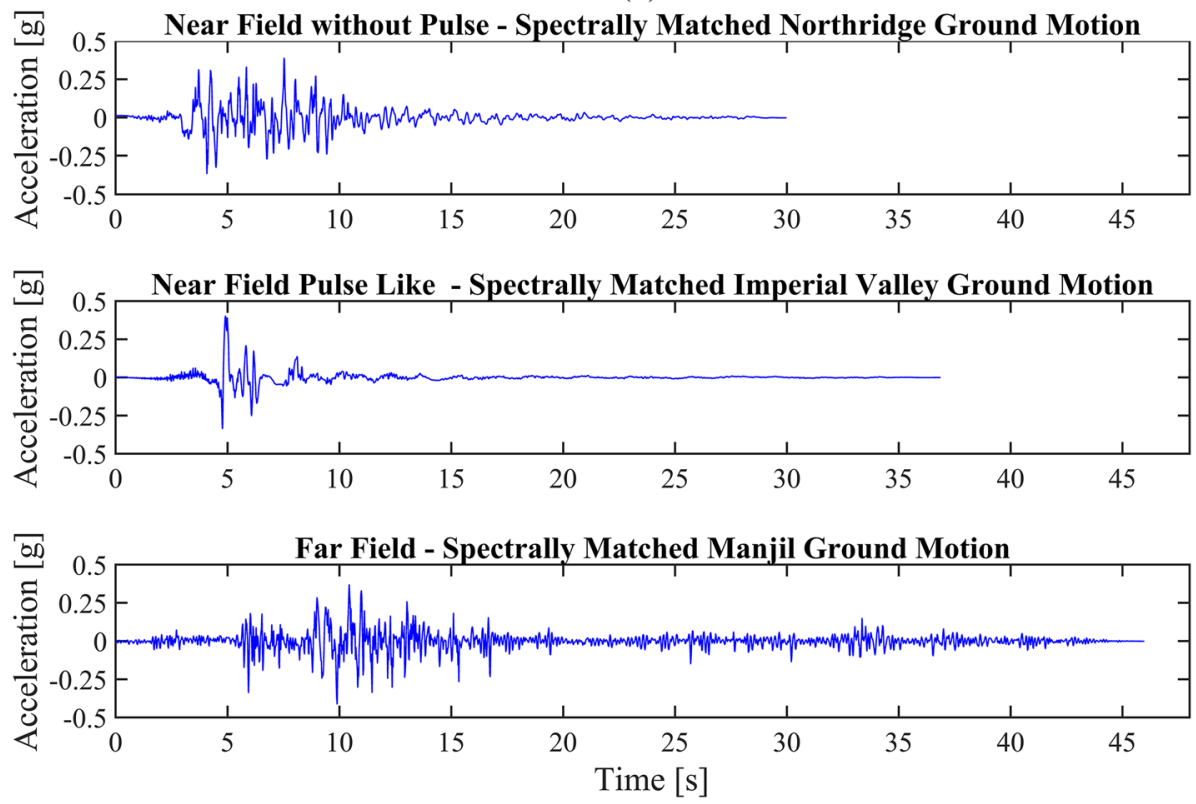

(b)

Fig. 5 Input ground-motions used in experimental testing: a target and matched response spectra, and b matched ground-motions 
the experimental testing. Further details of ground-motion selection and matching process are available (Kashani et al. 2017a).

In order to investigate various levels of damage and the influence of ground-motion type and duration on the cyclic degradation of the material, four intensity levels are considered. The shaking intensity levels correspond to slight, extensive and complete damage limit states, and the fourth shake is a strong aftershock sequence. Prior to the first test and after every intensity level of shaking a low amplitude white-noise test is conducted to quantify the natural frequency and dynamic properties of test specimens at each damage level. Details of the experimental testing sequences are summarised in Table 2. The excitation levels in Table 2 correspond to the scale factors used in the ground-motions. For example, $300 \%$ excitation indicates the scale factor of 3 .

\section{Experimental results and discussion}

\subsection{Force-displacement hysteretic response and structural damage}

Figure 6 shows a normalised force-displacement hysteretic response of the well-confined column subject to NFPL ground-motion at each damage limit state excitation level. The base shear is normalised to the weight (axial force) on the column $(30 \mathrm{kN})$, and displacement is normalised to height; i.e. drift ratio in percentage. Figure $6 \mathrm{a}$, e shows that, as expected, at $25 \%$ excitation the response is within the linear range and results in some very minor cracks. Figure $6 \mathrm{~b}$, f shows, at significant damage limit state shaking (300\% excitation), that the column experiences severe damage and that at this level concrete cover has spalled off and vertical reinforcement yielded. Figure $6 c$, g shows a significant growth in the hysteretic loops. At this stage, the core confined concrete started to crush and the column experienced a significant residual drift without any sign of buckling of the vertical reinforcement. Figure $6 \mathrm{~d}$, h shows cyclic degradation in hysteric loops due to low-cycle fatigue damage in steel and some crushing of the core confined concrete.

Figure 7 shows the qualitative comparison of the structural damage in all the columns at the severe damage limit state shaking (300\% excitation). The results show that the maximum peak responses (maximum drifts) in all the columns are qualitatively similar. Figure $7 \mathrm{a}, \mathrm{c}, \mathrm{d}$ suggest that damage occurs over a longer duration than for the case of NFPL Fig. $7 \mathrm{~b}$ case. Comparing Fig. $7 \mathrm{c}, \mathrm{d}$ also shows that the lightly-confined column experienced more cyclic degradation than the well-confined column subject to FF ground-motion. We will quantify and discuss these observations further in Sects. 3.3 and 3.4 of this paper.

Table 2 Experimental test matrix

\begin{tabular}{llllll}
\hline Specimen types & Ground-motion & \multicolumn{2}{l}{ Ground-motion intensity } & \\
\cline { 3 - 6 } & & Slight-25\% & Extensive-300\% & Complete-500\% & Aftershock-300\% \\
\hline 1. Well confined & Northridge & NFWP-R1 & NFWP-R2 & NFWP-R3 & NFWP-R4 \\
2. Well confined & Imperial Valley & NFPL-R1 & NFPL-R2 & NFPL-R3 & NFPL-R4 \\
3. Well confined & Manjil & FF-WC-R1 & FF-WC-R2 & FF-WC-R3 & FF-WC-R4 \\
4. Lightly confined & Manjil & FF-LC-R1 & FF-LC-R2 & FF-LC-R3 & FF-LC-R4 \\
\hline
\end{tabular}




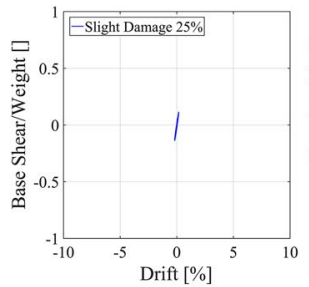

(a)

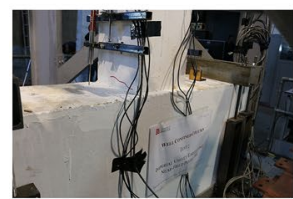

(e)

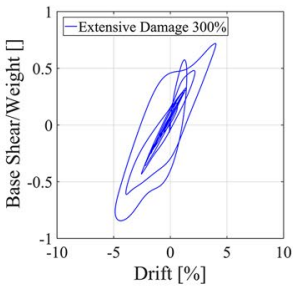

(b)

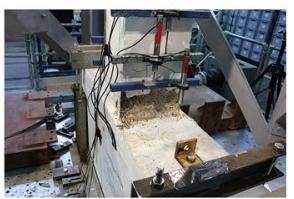

(f)

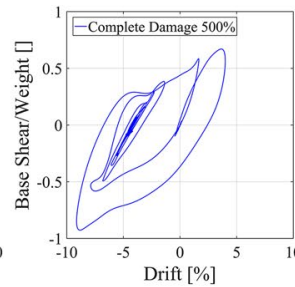

(c)

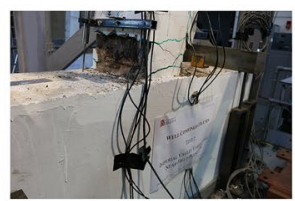

(g)

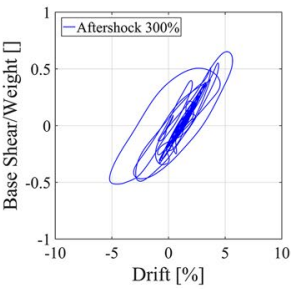

(d)

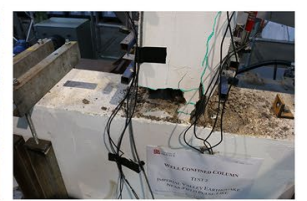

(h)

Fig. 6 Force-displacement hysteresis response column 2 under NFPL ground-motion at different damage limit states: a, e slight damage ( $25 \%$ excitation), b, f extensive damage ( $300 \%$ excitation), c, $\mathbf{g}$ complete damage (500\% excitation), and $\mathbf{d}, \mathbf{h}$ aftershock (300\% excitation)

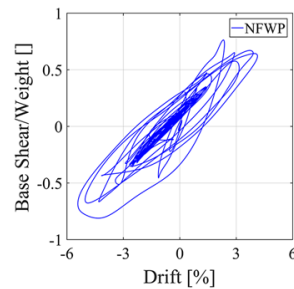

(a)

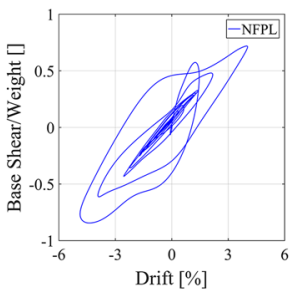

(b)

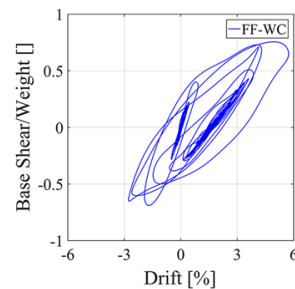

(c)

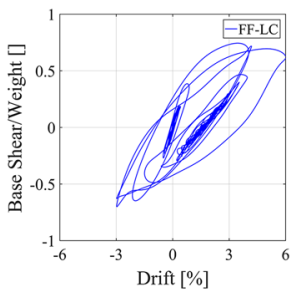

(d)

Fig. 7 Force-displacement hysteresis response of all RC columns at 300\% excitation (extensive damage): a column 1 NFWP, b column 2 NFPL, c column 3 FF-WC, d column 4 FF-LC

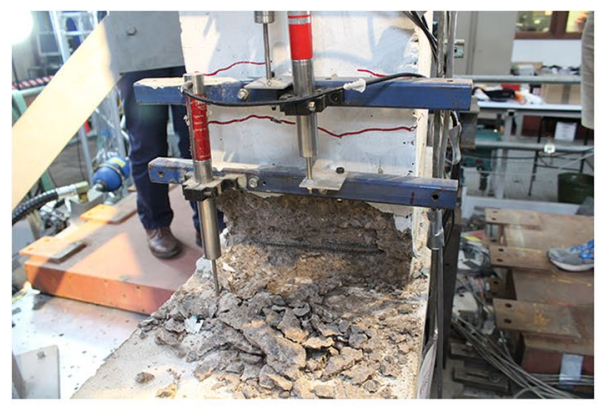

(a)

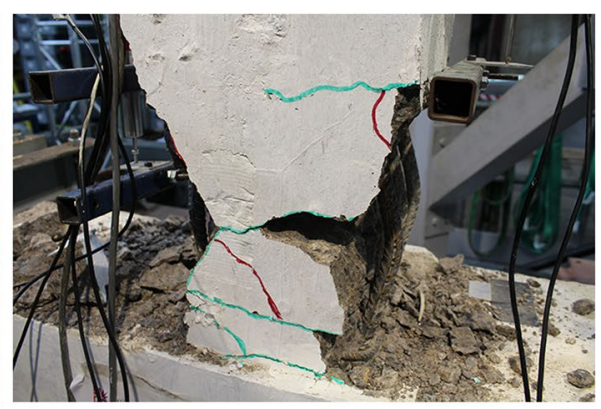

(b)

Fig. 8 Structural damage in FF-WC and FF-LC columns at 500\% excitation (complete damage): a FF-WC and b FF-LC 
Figure 8a shows the damage in well-confined (FF-WC) column 3 and Fig. 8b shows the lightly-confined (FF-LC) column 4 after the complete damage limit state shaking (500\% excitation). The visual inspection of damage indicates that severe buckling of the vertical bars in the lightly confined columns results in premature crushing of the core concrete. This consequently results in severe degradation in the hysteretic response of the column. These results are in good agreement with previous shaking table experiments of RC columns (Laplace et al. 1999; Phan et al. 2007; Brown and Saiidi 2011). In the following sections of this paper, we will discuss these results in detail and quantify the structural damage using innovative signal processing techniques.

\subsection{Transfer function estimate of the response}

Power Spectral Density (PSD) is normally used to characterise the frequency content of a time-series (Cryer and Chan 2008). Power spectral estimates are useful in a variety of applications, including system identification white noise tests. The PSD can quantify the periodic pattern, if there is any, in a time-series by determining the peaks, in frequency, which corresponds to these periodicities. Given a linear system, with a known excitation and response, we can perform a system identification by estimating the transfer function. This transfer function estimate makes use of auto and cross power spectral densities, using Welch's (1967) algorithm. This algorithm involves (1) dividing both signals into a number of overlapping sections, (2) weighting each section with a window function to attenuate the influence of leakage, (3) Fast Fourier transforming the windowed section time-series and (4) average all windowed sections which increases the signal to noise ratio. Longer, stationary, time-series permit greater noise reduction and higher frequency resolution of the transfer function estimate.

In this study, a long duration (2.5 min), low amplitude ( $0.0043 \mathrm{~g})$, white noise groundmotion shaking tests are conducted on the pristine column and after each level of excitation. It should be noted that at these low amplitudes it is unlikely that there will be opening and closing of cracks, i.e. at this strain amplitude the system is linear. Figure 9 shows the transfer function estimate (Vold et al. 1984) of all columns at every stage of the experiments. The first and second modes are clearly seen in all tests. Higher modes are just about detectable, but above $100 \mathrm{~Hz}$ experimental noise is significant even with averaging. A large drop in the first and second modal frequencies is observed when moving from 25 to $300 \%$ excitation levels (extensive damage). In other words, extensive damage does produce an observable reduction in system frequencies. However, there is not any significant change in the system natural frequency when moving from 300 to $500 \%$ excitation level (complete damage).

The change in natural frequency, at $300 \%$, is mainly due to significant damage to the concrete cover. The drop in system frequencies due to the cover damage and spalled concrete can only occur once. Therefore, we see no significant further reduction in system frequencies at the 500\% excitation level. It appears that damage to reinforcing steel does not have a significant contribution to the change of natural frequencies. This finding is based on the consistent results in all columns. Only column 4 (FF-LC) showed a more significant drop in its natural frequency at $500 \%$ excitation. This is due to damage of the vertical rebars in the form of inelastic buckling (Fig. 8b) and incipient crushing of the core/confined concrete. Thus, generally reinforcing steel may not directly contribute to the reduction of natural frequency for well-designed columns. However, poor reinforcement detailing results in severe inelastic buckling, premature concrete cover, spalling and core concrete crushing, 


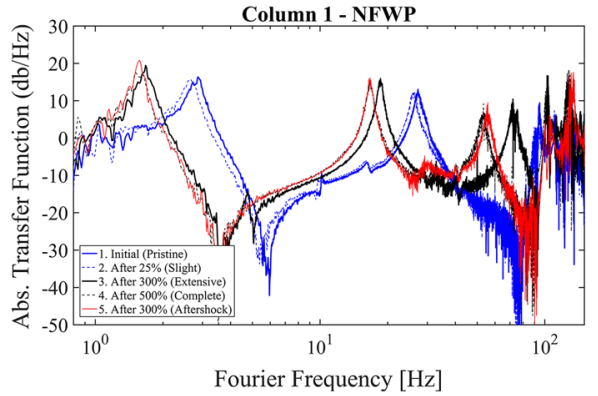

(a)

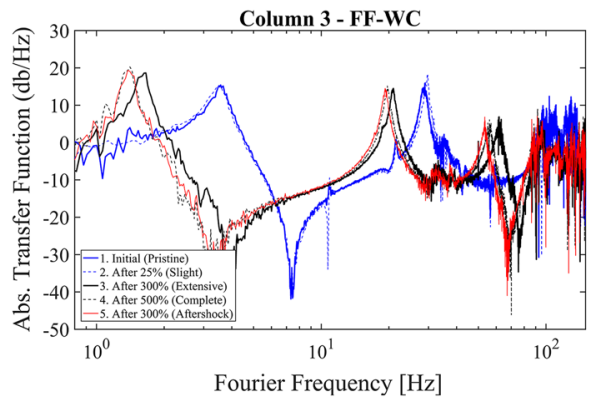

(c)

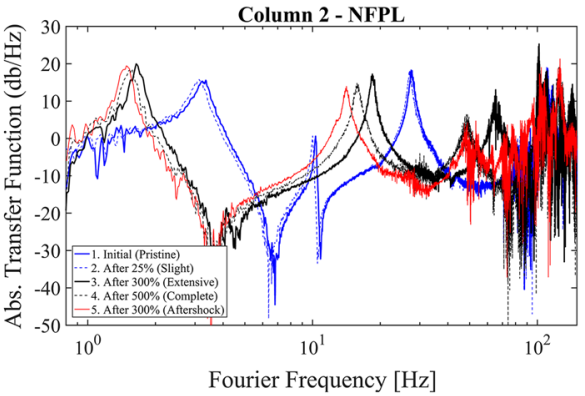

(b)

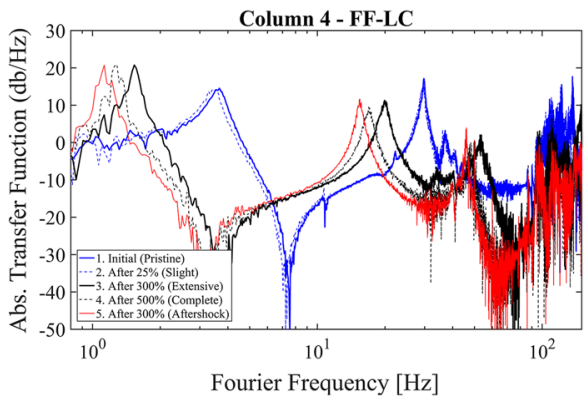

(d)

Fig. 9 Transfer function estimate of white noise excitations for all columns: a column 1 NFWP, b column 2 NFPL, c column 3 FF-WC, and d column 4 FF-LC

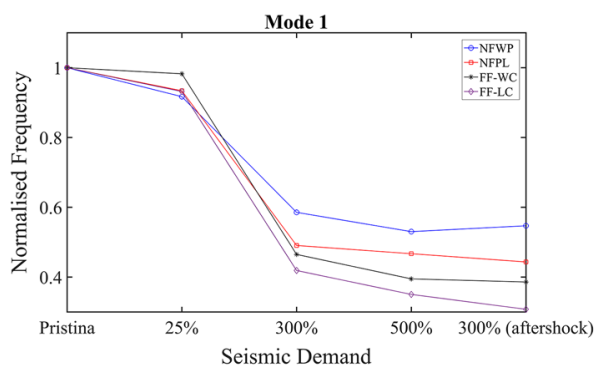

(a)

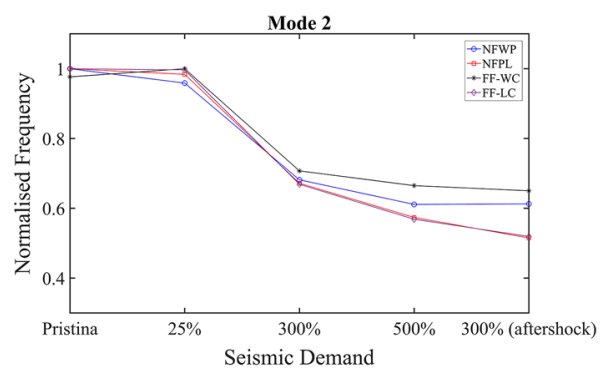

(b)

Fig. 10 Frequency variant of mode 1 and mode 2 : $\mathbf{a}$ mode 1 , and $\mathbf{b}$ mode 2

which subsequently has more significant effect on the reduction of natural frequency. This is further clarified in Fig. 10, where the trend line drop in frequency of first and second modes are shown. The frequency values in graphs in Fig. 10 are normalised to their corresponding values of pristine columns. Figure 10a shows that after $300 \%$ excitation the frequency of the first mode drop to between 40 and $60 \%$ of their initial pristine columns values. Unsurprisingly, column 4 (FF-LC) has the largest drop in natural frequencies. Figure $10 \mathrm{~b}$ shows that the drop in the frequency of the second mode is less severe than the first mode. The severe damage due to the buckling of reinforcement and incipient core concrete crushing does not have a significant impact on the frequency drop of the second mode. 


\subsection{Time-frequency analysis using Wigner-Ville distribution algorithm}

In Sect. 3.2, we used the transfer function estimate to quantify the impact of structural damage due to material nonlinearity and cyclic degradation on the natural frequency of the structure (frequency of first and second mode). However, the transfer function estimate quantifies the change in frequency before and after seismic tests but not during a seismic test. Investigating the effects of the non-stationary content of ground-motion on (1) structural damage and (2) system frequencies during earthquakes, require time-frequency analyses of the response. Exploration of time-frequency content of a time series can be estimated using, for example, the short-time Fourier transform, the Hilbert transform, and the continuous wavelet transform. However, in this paper we found the Wigner-Ville distribution (WVD) (Cohen 1994; Semmlow and Griffel 2009) has the greatest utility as it allowed a higher resolution in both time and frequency.

Consider the upper panel of Fig. 11d which displays the ground-motion and top mass acceleration time-series for $300 \%$ excitation level (for Column 4). The colour contour plot (contour levels in power), in the lower panel of Fig. 11d, is the power-time-frequency plot for the top mass acceleration time-series. This power-time-frequency plot is obtained using the pseudo-smoothed WVD algorithm in MATLAB (1994-2017) in a form of a toolbox, which is
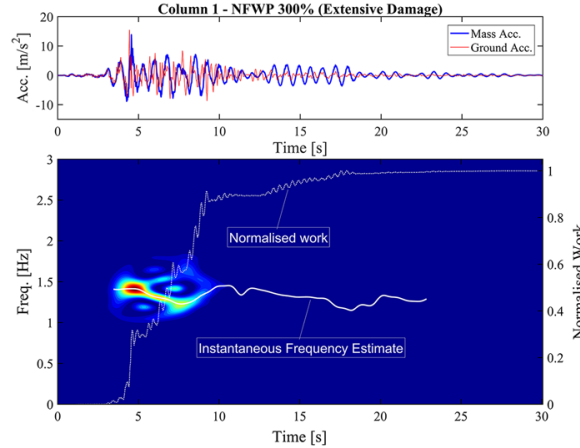

(a)
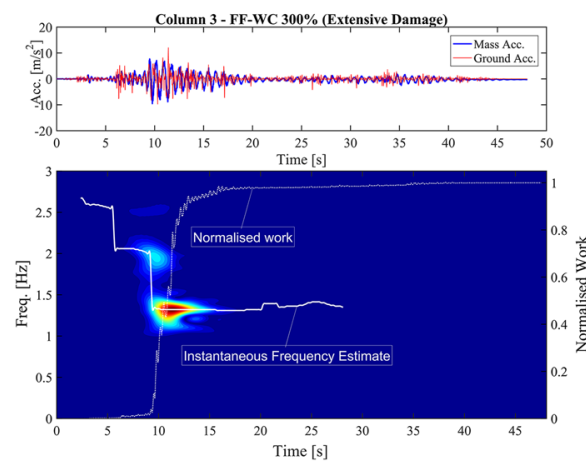

(c)
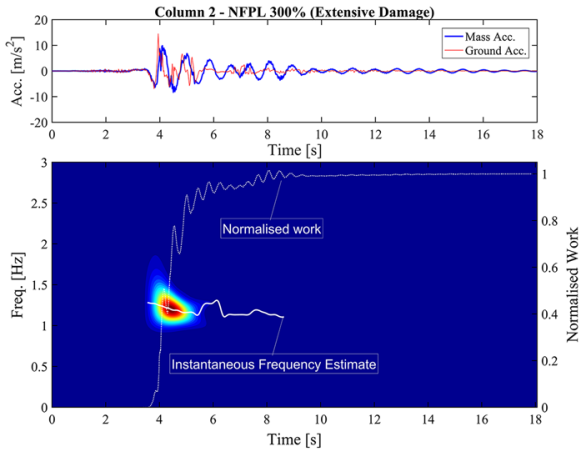

(b)
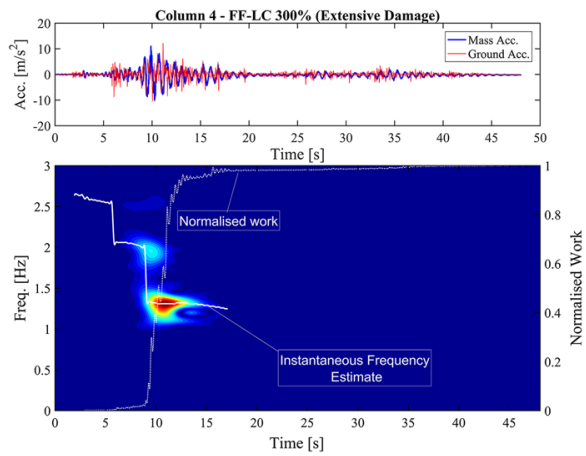

(d)

Fig. 11 Time-frequency analysis using Wigner-Ville distribution algorithm: a well-confined column under NFWP, b well-confined column under NFPL, $\mathbf{c}$ well-confined column under FF, and d lightly confined column under FF 
developed by Auger et al. (1996). The maxima, at a given frequency and above a significance threshold, is plotted as a solid white line (termed here the instantaneous frequency estimate). This line depicts the nonlinear variation in response frequency of the column during the test. Columns 3 and 4 exhibit a clear sudden reduction in their instantaneous frequency estimates during the first large pulse in ground-motion history. These sudden drops in frequencies are suggestive of large cracking in the cover concrete.

Additionally, the values of dissipated energy (work) are also shown in Fig. 11. The method used in the calculation of this energy is available in Sect. 3.4 of this paper. This dissipated energy is essentially the integral of the force/deflection loop. The large increases in normalised work (which are computed with both response displacement and acceleration time-series) are well correlated with the large power in the WVD (which are computed using response accelerations alone). In Fig. 11c, d, for columns 3 and 4, the instantaneous frequency estimates suggest that large cracks form in the cover far earlier, in time, than the dissipated energy damage measure implies. This is because the instantaneous frequency estimate reports information about crack formation while the dissipated energy damage measure calculates the work done in opening/closing these cracks and yielding of steel.

Figure 11 also shows that the response frequency can increases again after these first large drops in frequency. It is not clear whether this is an artefact of the WVD algorithm or due to pieces of broken concrete between the cracks. In Fig. 11a the increase in instantaneous frequency from 7 to $10 \mathrm{~s}$ is at reasonably high-power levels so is most probably not an artefact of the WVD algorithm. This, therefore, points to a physical explanation. During the column damage process, the concrete cover and part of the core concrete begin crushing. In this cyclic degradation process, parts of concrete pieces remain within the cracks. Therefore, in the subsequent cycles, the concrete pieces between cracks prevent complete crack closure and stiffen the whole structure. Evidence for this phenomenon is seen during the experiment. This has been reported by other researchers (Stanton and McNiven 1979; Kwan and Billington 2003; Lee and Billington 2009). The incomplete crack closure has a major impact on the cross over displacement and residual drift of the RC columns. It is very difficult to be quantified numerically (Lee and Billington 2009). Furthermore, we concluded that the drop in the response frequency of the RC columns is mainly governed by the damage in concrete. Therefore, it is important to investigate the influence of concrete cover thickness. This is an area for future work, and the results of this study provide a set of experimental data set for other researchers in the future research. Additionally, using high-speed/resolution video footage of the plastic zone would be very useful in future work.

\subsection{Time-cumulative damage and effective duration analysis}

Several researchers have investigated the influence of ground-motion duration on structural performance and cumulative damage of RC structures (Bommer and Martinez-Pereira 1999; Hancock and Bommer 2006; Iervolino et al. 2006; Hancock and Bommer 2007; Raghunandan and Liel 2013). Previous research into this topic has produced mixed conclusions, and hence, the effect of ground-motion duration has been largely ignored in the seismic design of structures. Among different metrics, the Arias integral (Arias 1970) is a widely used and shown in Eq. (1).

$$
I_{A}(t)=\frac{\pi}{2 g} \int_{0}^{t} a_{g}^{2} d t
$$


where $a_{g}$ is the ground-motion acceleration time-series, $g$ is the acceleration gravitational constant and $I_{A}(t)$ is the Arias integral at time $t$ of the time-series $a_{g}$. The original Arias Intensity $\left(I_{A}\right)$ (Arias 1970) definition was the integral value, Eq. (1), at end of the earthquake time-series. A graph of this integral vs time it is known as a Husid plot. The initial idea (Arias 1970) was to determine the time points $t_{0}$ and $t_{1}$, which corresponds to $5 \%$ and $95 \%$ of the Arias Intensity. In this case, the effective duration $D$ would be simply defined as $D=t_{1}-t_{0}$. The confidence limits of $5-95 \%$ are typically used statistically for Gaussian random processes. However, it would be more reasonable to use these confidence limits on the structural response (a damage measure) rather than the excitation of the structure (an intensity measure). This is because structural engineers are ultimately interested in damage levels. Let us assume that we use confidence limits of 5-95\% on some structural response (damage measure) to define an effective duration $D^{\prime}$. What confidence limits should we employ on my intensity measure to get the same effective duration $D^{\prime}$ ? Foschaar et al. (2012) suggested employing 5-75\% of the Arias Intensity. However, the stationary/nonstationary content of ground-motion and the structural system may have a large influence the choice of these suggested confidence limits (Chandramohan et al. 2016; Raghunandan and Liel 2013; Kempton and Stewart 2006). In this experiment, the stationary content of the ground-motion for all tests (as they are spectral matched) is very similar. Therefore, we remove the large variance due to the stationary content to quantify the influence of the nonstationary content alone on effective duration estimates.

In this study, the hysteretic energy is used as a damage measure to quantify the cumulative damage in the RC columns. Confidence limits of 5-95\% on this damage measure are then employed to determine the time points $t_{0}$ and $t_{1}$, hence effective duration can be determined. We will then explore what confidence limits should be used on the Arias Intensity to produce the same effective duration. Finally, we will explore whether there is any evidence to suggest these confidence limits on the Arias Intensity should depend on the nonstationary class of ground-motion (i.e. NFPL, NPWP, FF).

A nonlinear single degree of freedom idealisation of the experimental model is described as follows:

$$
m\left(\ddot{x}+\ddot{x}_{g}\right)+F(x, \dot{x}, t)=0
$$

Hence, the cumulative work done (dissipated energy), $W$, can be calculated by evaluating the integration in Eq. (3).

$$
W=\int m\left(\ddot{x}+\ddot{x}_{g}\right) \mathrm{d} x=-\int F(x, \dot{x}, t) \mathrm{d} x
$$

where $m$ is modal mass, $F$ is the base shear, $t$ is time, and $x$ is the response displacement. Chopra (2016) additionally removes linear elastic and damping energy terms. However, it should be noted that in this experimental case, we do not know precisely the damping model, nor the initial stiffness of the column (under larger amplitudes). Additionally, the experimental model is not a single degree of freedom system. Hence, we use an approximation, Eq. (3), and recognise some small oscillations are due to the limitation described in the previous sentences.

Figure 12 shows the normalised $W$ and $I_{A}$ over the whole duration of ground-motion at $300 \%$ excitation level. In Fig. 12, $W$ and $I_{A}$ are normalised to their corresponding maximum values. In order to quantify the effective duration of ground-motions, we choose the confidence limits of $5 \%$ to $95 \%$ of $W$ (i.e. 5-95\% of actual cumulative structural damage). Then, identify time points $t_{0}$ and $t_{1}$, hence effective duration. We then determine the confidence 


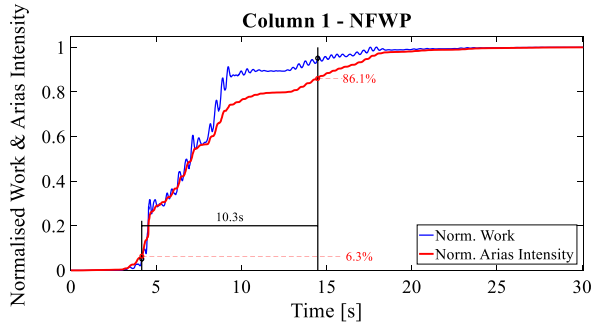

(a)

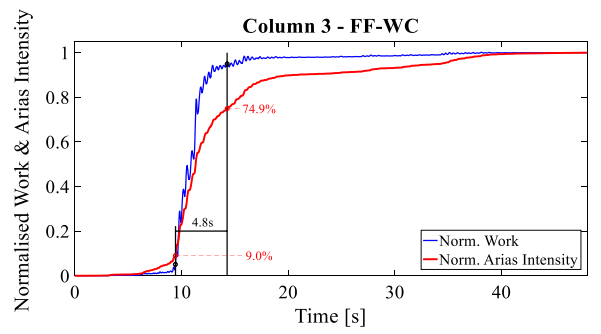

(c)

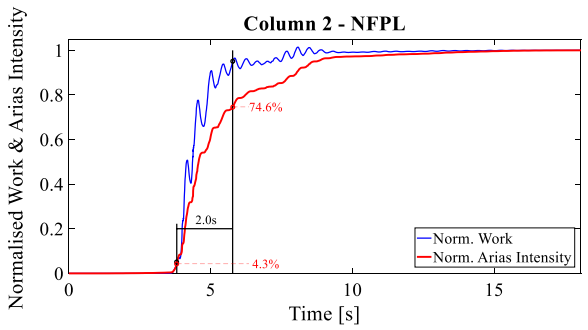

(b)

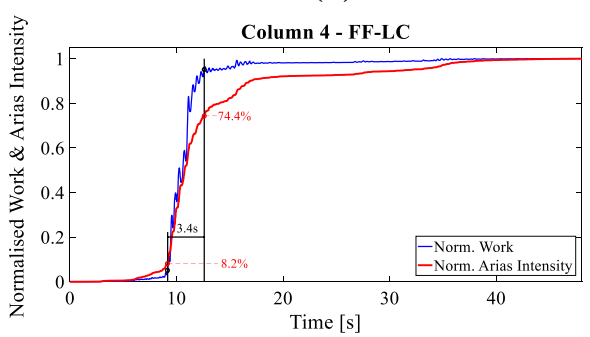

(d)

Fig. 12 Identifying effective ground-motion duration: (a) column 1-NFWP ground-motion, b column 2NFPL ground-motion, c column 3-FF-WC and $\mathbf{d}$ column 3-FF-LC

limits on $I_{A}$ graphs that would result in the same time points and effective duration estimate. The results are shown in Fig. 12b (NFPL) demonstrate that 5-75\% of the Arias Intensity provides a good estimate of the effective duration of ground-motion. This is in a good agreement with the initial numerical study by Foschaar et al. (2012). However, Fig. 12a (NFWP) 5-85\% might be a better set of confidence limits.

Comparison of Fig. 12a with Fig. 12c, d shows that even though the FF ground-motion is longer (in seconds) its effective duration is smaller than the NFWP. This suggests that the work done in opening/closing cracks occurs over a longer duration for the NFWP record. Furthermore, comparing Fig. 12c, d shows that structural detailing does not have a significant influence on effective duration of ground-motion at this level of excitation.

\subsection{Time-effective stiffness degradation analysis}

The stiffness degradation of a structure is an important parameter that affects the response of the system under earthquake excitation. Since RC structures crack, reinforcement yield, and due to low-cycle fatigue they suffer from material cyclic degradation, they have a nonlinear softening type behaviour. This softening type behaviour affects the response, and it is important to quantify how and when the most significant stiffness degradation occurs during an earthquake. In this study, the time-varying stiffness is calculated by fitting a least-squares straight line to force-deflection loop over a moving $2 \mathrm{~N}$ point window for the entire groundmotion (Eq. (4)).

$$
\left[\begin{array}{c}
F_{i-N} \\
\vdots \\
F_{i+N-1}
\end{array}\right]=\left[\begin{array}{cc}
1 & x_{i-N} \\
\vdots & \vdots \\
1 & x_{i+N-1}
\end{array}\right]\left[\begin{array}{c}
c_{i} \\
K_{i}
\end{array}\right]
$$


where $F_{i}$ are the base shear (that is determined by inertial forces $F_{i}=-m\left(\ddot{x}_{i}+\ddot{x}_{g}\right)$ ) and $x_{i}$ mass displacement response at the time $t_{i}$. $K_{i}$ is the time-varying stiffness estimate and $c_{i}$ is the time varying residual displacement at the time $t_{i}$. Equation (4) is solved using single value decomposition. The window length over which this averaging is performed is taken as $1 \mathrm{~s}$. Thus, $N=f_{s} / 2$ where $f_{s}$ is sampling frequency.

Figure 13 shows the normalised time-stiffness graphs of all columns. The flexural stiffness of each column is calculated using Eq. (4), which is normalised to the

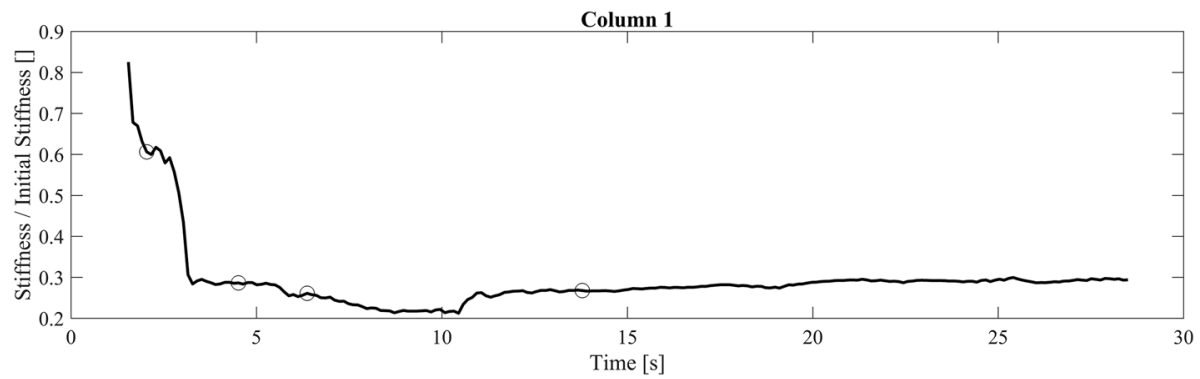

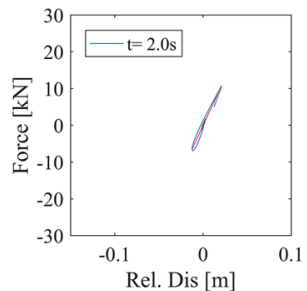

Rel. Dis $[\mathrm{m}]$

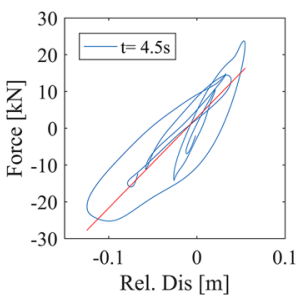

(a)

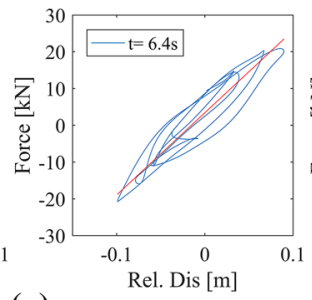

a)

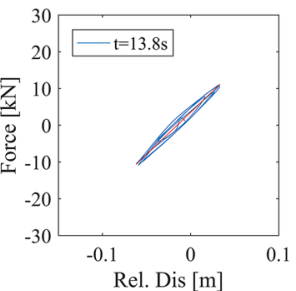

Rel. Dis $[\mathrm{m}]$

Column 2
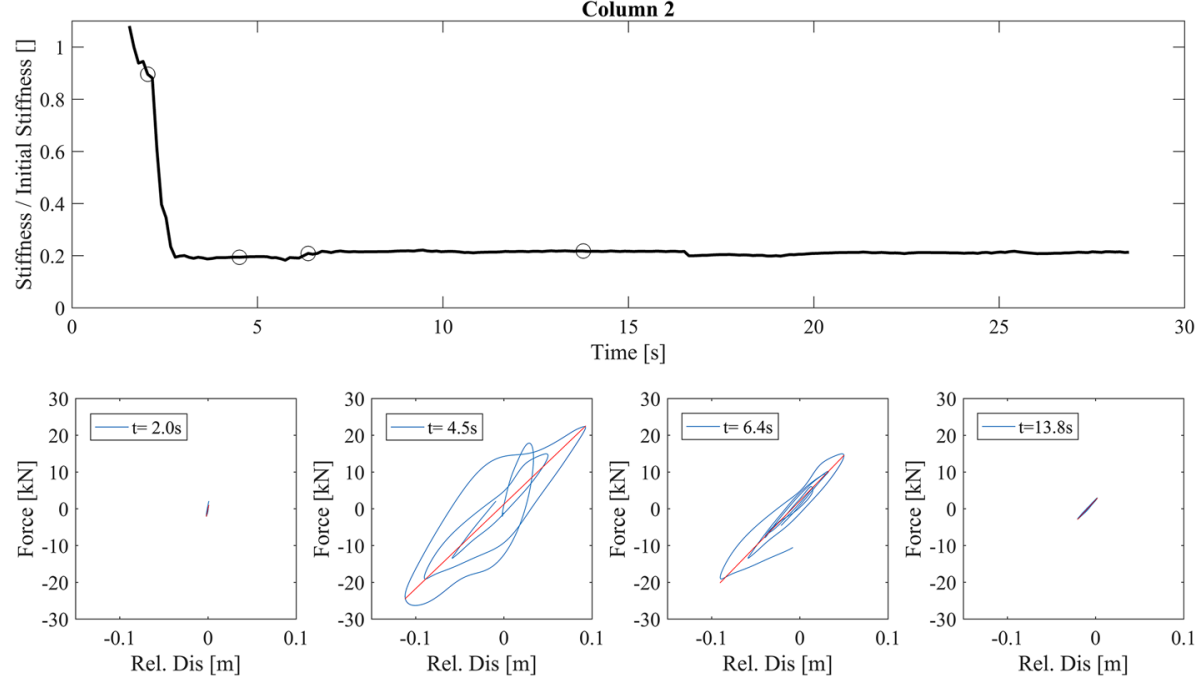

(b)

Fig. 13 Effective stiffness degradation of all columns at $300 \%$ excitation (extensive damage): a column $1-$ NFWP, b column 2-NFPL, $\mathbf{c}$ well confined column under FF, and $\mathbf{d}$ lightly confined column under FF) 

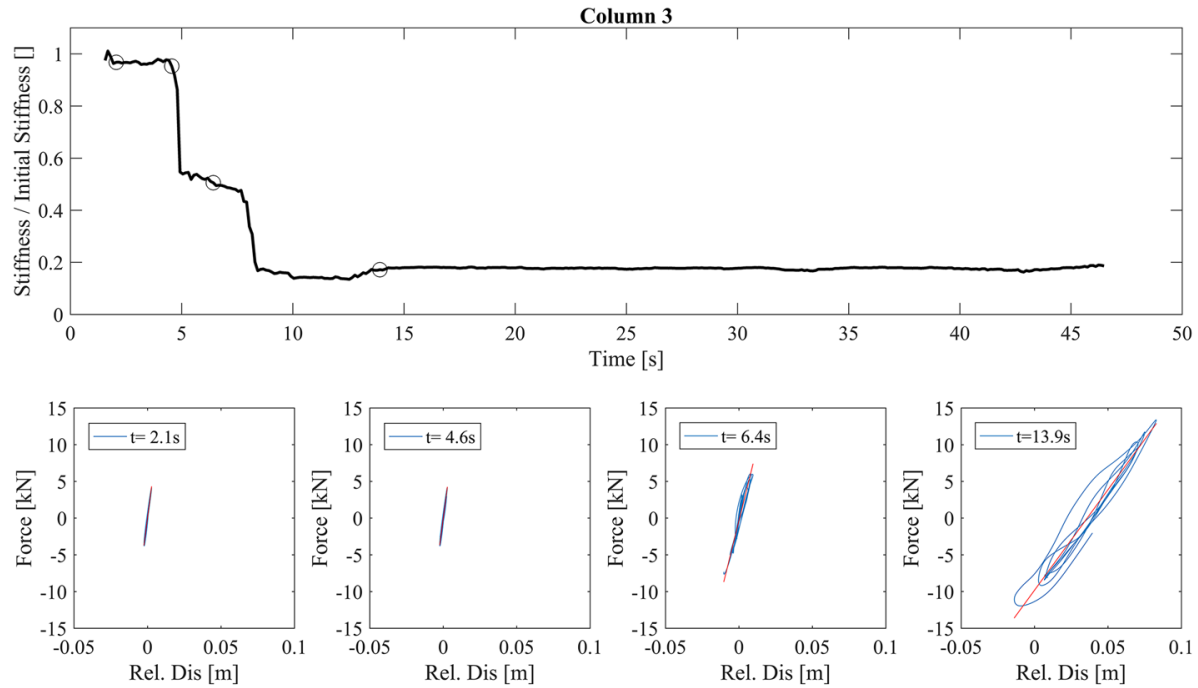

(c)

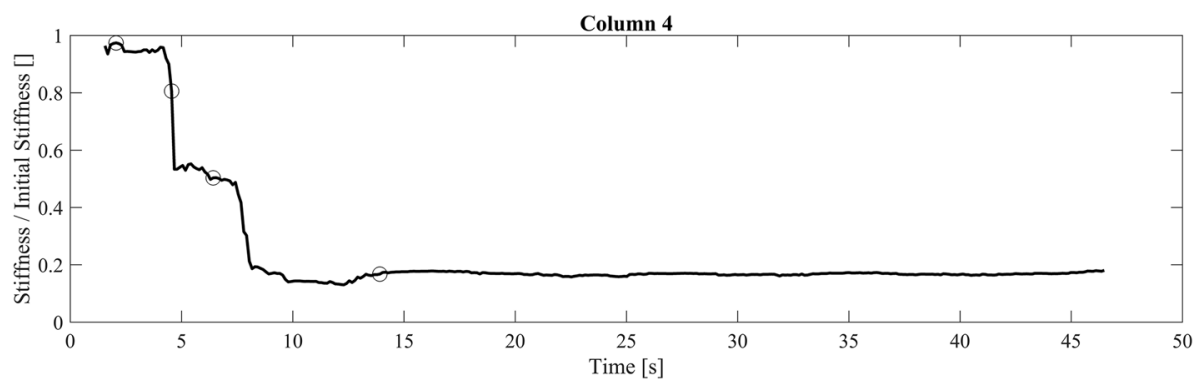

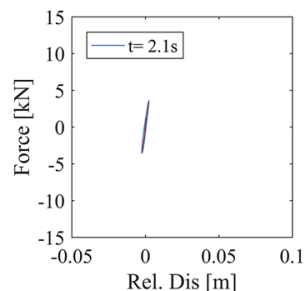

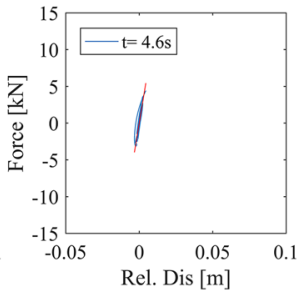

(d)
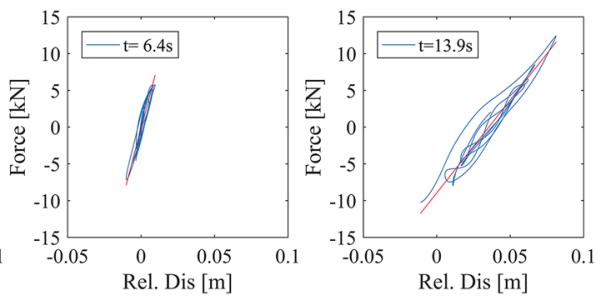

Fig. 13 (continued)

estimated flexural stiffness of the pristine RC column (using the initial white noise test data). Figure 13a shows a large drop in the first stiffness during the first $4 \mathrm{~s}$ of the earthquake. Comparing this with Fig. 11a demonstrates that the drop in stiffness and frequency occur at the creation of cracks, which seems to occur before the arrival of the maximum of the first peak of the ground-motion. Figure 13a also shows the gain in stiffness after $8 \mathrm{~s}$ which is similar to that observed in Fig. 11a with the instantaneous frequency estimate. Thus, suggestive that this gain in stiffness is due to material falling into open cracks that inhibit closure. 
Comparing Fig. 13c with Fig. 11c and Fig. 13d with Fig. 11d underlines that (1) the instantaneous frequency estimates (Sect. 3.3, based acceleration responses alone) is a good measure of loss of stiffness, (2) this loss of stiffness is due to crack formation (3) this crack formation occurs before the large energy dissipation due to open/closing cracks and steel yielding.

Figures 13 shows that the minimum stiffness in all the columns (regardless of groundmotion type and reinforcement detail) after the earthquake is about $20 \%$ of the uncracked elastic stiffness of the pristine column. This is very important finding and can be used in numerical/analytical studies using simplified low-order models (single/multi degree of freedom models with nonlinear springs) to account for stiffness degradation of the structure.

\subsection{Influence of ground-motion type and duration on peak response}

Several researchers investigated the influence of ground-motion duration on peak displacement response of RC structures (Hancock and Bommer 2006). Hancock and Bommer (2006) concluded that the ground-motion duration does not have a significant influence on the peak displacement response. In contrast, Chandramohan et al. (2016) concluded that peak displacement response of RC structures is higher in long-duration ground-motion than spectrally equivalent short-duration ground-motions. In this section, we discuss if the ground-motion type and duration have any influence on peak displacement response of RC columns using experimental results.

The peak drift ratios (displacement response) of all columns under different groundmotion intensities are shown in Fig. 14. Figure 14 shows that there is a small difference between peak displacement responses of columns subject to different ground-motions at extensive damage limit state (300\%). The results show that the peak response of FF ground-motions is about $8 \%$ higher than NFWP and NFPL ground-motions at $300 \%$ excitation. However, the peak response of NFWP and NFPL is about 35\% higher than FF ground-motions at complete damage limit state excitation (500\%).

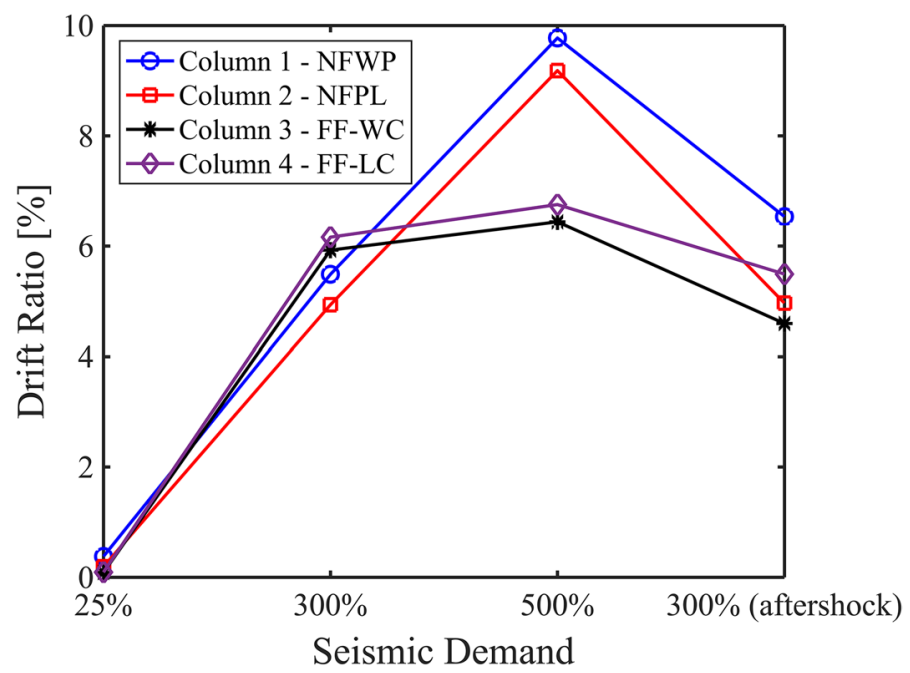

Fig. 14 Peak displacement response of all columns under different ground-motions 
To explore this further, Fig. 15 shows the normalised base shear versus drift ratios of all columns at $500 \%$ excitation. Figure 15 a shows that the column 1 subject to NFWP groundmotion, which also has the longest significant duration compare to the other two, has the largest drift and the most severe cyclic degradation. Figure $15 \mathrm{~b}$ shows that the column 2 subject to NFPL ground-motion also has a similar drift, but not very much cyclic degradation, as the significant duration of the ground-motion is very short (it is only a pulse). Comparing Fig. 15c, d shows that the column 3 (well-confined) subject to FF ground-motion has slightly smaller drift and has slightly less cyclic degradation in comparison to column 4 (lightly-confined), which experience severe inelastic buckling of vertical bars (as previously shown in Fig. 8). This firstly shows that, although the FF ground-motion has the longest total ground-motion record, the effective duration of FF ground-motion is less than NFWP, and hence the damage is less severe than NFWP and NFPL ground motions. Furthermore, the cyclic hysteretic responses of the well- confined and lightly-confined columns in Fig. 15c, $\mathrm{d}$ are very similar (despite the sever inelastic buckling observed in the lightly-confined column). In an earlier numerical exploration study by the first author (Kashani et al. 2017a), we found that the degradation in cyclic hysteretic response due to inelastic buckling is influenced by the column height. Kashani et al. (2017a) investigated the dynamic and cyclic responses of three columns with three different shear span to depth ratios [4, 8, and 10] (all flexural dominant columns) under the same suite of ground motions as this experiment. We found that as the column height increases the failure mode is mainly governed by second order effect and yielding and/or fracture of the vertical bars in tension (shear span depth to ratio more than 8 ). The effect of inelastic buckling on the cyclic hysteretic response is more pronounced in columns with small shear span to depth ratios (shear span depth ratio less than 5), where the failure in mainly governed by inelastic bucking and core concrete crushing, followed by fracture of bars in tension. The shear span to depth ratio of our columns in this experiment is 10, which is in good agreement with our findings in the earlier numerical exploration study (further discussion of is available in Kashani et al. 2017a).

These results confirm that although all of these ground-motions are spectrally matched, the ground-motion type, duration, and reinforcement detail have a significant influence on nonlinear behaviour, structural damage, and subsequently peak displacement response of RC columns at large amplitude excitations. These results are in contrast with the numerical results obtained by Kashani et al. (2017a), where the same NFWP and NFPL groundmotions showed smaller peak displacement responses. The main difference between the numerical study (Kashani et al. 2017a) and the present experimental testing is the crosssectional shape of the columns. The columns studied in numerical analysis (Kashani et al. 2017a) are a circular cross section, but the columns in the current experimental programme are square cross-sections. In another study by authors (Kashani et al. 2017b), it is shown

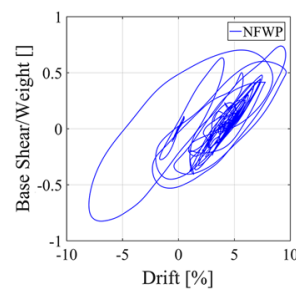

(a)

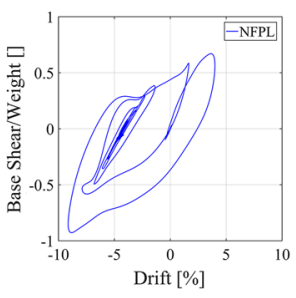

(b)

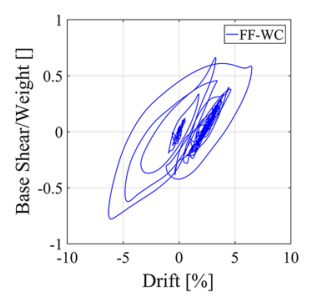

(c)

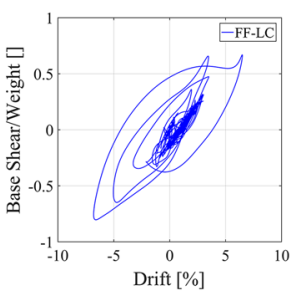

(d)

Fig. 15 Force-displacement hysteresis response of all RC columns at 500\% excitation (complete damage): a column 1 NFWP, b column 2 NFPL, c column 3 FF-WC, d column 4 FF-LC 
that cross section shape of RC columns has a significant influence on the nonlinear flexural response and failure mode. Considering the complexities and uncertainties in groundmotion characteristics and limitations in numerical models, it is very difficult to find a solid correlation between the ground-motion duration and peak displacement response. Therefore, there is a need for further detailed numerical and experimental studies in future research to close this issue. However, the results of this experiments provide a good insight into this problem and allow other researchers to use these experimental data as a platform for verification of numerical models.

\section{Conclusions}

A set of benchmark large-scale shaking table tests is conducted at the University of Bristol, to investigate the impact of the non-stationary content of ground-motion on the structural damage of RC columns and significant duration of ground-motion. To examine the influence of ground-motion characteristics, three identical RC columns are tested under spectrally matched (1) near-field without pulse, (2) near-field pulse-like, and (3) far-field ground-motions. The main conclusions of this study are as follows:

1. The transfer function estimate shows that concrete cover spalling is the main factor governing the natural frequency drop in RC columns. This shows that yielding and plasticity in reinforcing steel does not have any significant influence on the inelastic frequency of the RC columns. However, if the RC column is poorly detailed and suffers from the inelastic buckling of vertical bars, then the concrete cover spalls more quickly and core concrete crushes soon after bar buckling.

2. The time-frequency analysis WVD and time-varying stiffness analyses show a small increase in the response frequency after the main drop due to crack formation. This is probably due to the influence of concrete pieces trapped within cracks, which prevent the complete crack closure. This phenomenon also has a significant impact on the cross over displacement and residual drift of RC columns. This conclusion is in good agreement with the results reported by other researchers who conducted static cyclic experiments and numerical modelling of RC columns (Stanton and McNiven 1979; Kwan and Billington 2003; Lee and Billington 2009).

3. The time-cumulative damage (dissipated energy based on force-displacement integral) and the Arias integral (squared acceleration response integral, Eq. (1)) are well correlated with this simple structural system. Obtaining suitable confidence limits for effective duration estimate is difficult as it appears to be dependent on both structure and ground-motion time-series. The results show that confidence limits from 5 to $75-85 \%$ are reasonable, which is in partial agreement with initial numerical studies conducted by Foschaar et al. (2012).

4. The experimental results show that regardless of ground-motion type all RC columns experience a stiffness drop to about $20 \%$ of their elastic uncracked original stiffness.

5. Results indicate that (1) the instantaneous frequency estimates (Sect. 3.3, based acceleration responses alone) is a good measure of loss of stiffness, (2) this loss of stiffness is due to crack formation (3) this crack formation occurs before the large energy dissipation due to open/closing cracks and steel yielding.

6. It was found that the ground-motion type and duration affect the peak displacement response owing to the excitation amplitude. 
Open Access This article is distributed under the terms of the Creative Commons Attribution 4.0 International License (http://creativecommons.org/licenses/by/4.0/), which permits unrestricted use, distribution, and reproduction in any medium, provided you give appropriate credit to the original author(s) and the source, provide a link to the Creative Commons license, and indicate if changes were made.

\section{References}

Alexander NA, Chanerley AA, Crewe AJ, Bhattacharya S (2014) Obtaining spectrum matching time series using a reweighted volterra series algorithm (RVSA). Bull Seismol Soc Am 104(4):1663-1673

Arias A (1970) A measure of earthquake intensity. Massachusetts Institute of Technology, Cambridge

Auger F, Flandrin P, Gonçalvès P, Lemoine O (1996) Time-frequency toolbox. CNRS France-Rice University, 46, Paris

Bommer JJ, Martinez-Pereira A (1999) The effective duration of earthquake strong motion. J Earthq Eng 3(02):127-172

Bommer JJ, Martinez-Pereira A (2000) Strong motion parameters: definition, usefulness and predictability. In: 12th world conference on earthquake engineering. Paper No. 206

Brown B, Saiidi MS (2011) Investigation of effect of near-fault motions on substandard bridge structures. Earthq Eng Eng Vib 10(1):1-11

BS 4449 +A2 (2005) Steel for the reinforcement of concrete-Weldable reinforcing steel—bar, coil and decoiled product

Caltrans (2013) Seismic design criteria, version 1.7. California Department of Transportation, Sacramento

Carrea F (2010) Shake-table test on a full-scale bridge reinforced concrete column. Doctoral dissertation, University of Bologna, Bologna, Italia

CEN. EN (2008) Eurocode 2: design of concrete structures. CEN/TC 250

CEN. EN (2010) Eurocode 8 - Design provisions for earthquake resistance of structures-part 2: bridges. CEN/ TC 250

Chandramohan R, Baker JW, Deierlien GG (2016) Quantifying the influence of ground-motion duration on structural collapse capacity using spectrally equivalent records. Earthq Spectra 32(2):927-950

Chang GA, Mander JB (1994) Seismic energy based fatigue damage analysis of bridge columns: part I—evaluation of seismic capacity. NCEER

Chatfield C (2003) The analysis of time series: an introduction, 6th edn. Chapman and Hall/CRC, Cambridge

Chen Y, Feng MQ, Soyoz S (2008) Large-scale shake table test verification of bridge condition assessment methods. J Struct Eng 134(7):1235-1245

Chopra AK (2016) Dynamics of structures: theory and applications to earthquake engineering, 5th edn. Prentice-Hall, Upper Saddle River

Cohen L (1994) Time frequency analysis: theory and applications. Prentice Hall, Upper Saddle River

Cornell CA (1997) Does duration really matter? FHWA/NCEER Workshop on the National Representation of Seismic Ground-motion for New and Existing Highway Facilities. Burlingame, California

Cryer JD, Chan KS (2008) Time series analysis with applications in R, 2nd edn. Springer, Berlin

Domizio M, Ambrosini D, Curadelli O (2017) Nonlinear dynamic numerical analysis of a RC frame subjected to seismic loading. Eng Struct 138:410-424

Elwood KJ (2004) Shake table tests and analytical studies on the gravity load collapse of reinforced concrete frames. PEER report

FEMA P695 (2009) Quantification of building seismic performance factors. Federal Emergency Management Agency, Washington

Foschaar JC, Baker JW, Deierlein GG (2012) Preliminary assessment of ground-motion duration effects on structural collapse. In: Proceedings of the 15th world conference on earthquake engineering. Lisboa, Portugal

Han J, Sun X, Zhou Y (2017) Duration effect of spectrally matched ground-motion records on collapse resistance capacity evaluation of RC frame structures. The Structural Design of Tall and Special Buildings

Hancock J, Bommer JJ (2005) The effective number of cycles of earthquake ground-motion. Earthq Eng Struct D 34(6):637-664

Hancock J, Bommer JJ (2006) A state-of-knowledge review of the influence of strong-motion duration on structural damage. Earthq Spectra 22(3):827-845

Hancock J, Bommer JJ (2007) Using spectral matched records to explore the influence of strong-motion duration on inelastic structural response. Soil D Earth Eng 27(4):291-299

Iervolino I, Manfredi G, Cosenza E (2006) Ground-motion duration effects on nonlinear seismic response. Earthq Eng Struct D 35(1):21-38 
Johnson NS, Saiidi MS, Sanders DH (2006) Large-scale experimental and analytical seismic studies of a twospan reinforced concrete bridge system. Rep. No. CCEER-06-02, Center for Civil Engineering Earthquake Research, Department of Civil and Environmental Engineering/258, University of Nevada Reno, Reno, Nevada

Kashani MM (2014) Seismic performance of corroded RC Bridge piers: development of a multi-mechanical nonlinear fibre beam-column model. Ph.D. Thesis, University of Bristol, Bristol, United Kingdom

Kashani MM, Crewe AJ, Alexander NA (2013) Nonlinear stress-strain behaviour of corrosion-damaged reinforcing bars including inelastic buckling. Eng Struct 48:417-429

Kashani MM, Barmi AK, Malinova VS (2015a) Influence of inelastic buckling on low-cycle fatigue degradation of reinforcing bars. Constr Build Mater 94:644-655

Kashani MM, Lowes LN, Crewe AJ, Alexander NA (2015b) Phenomenological hysteretic model for corroded reinforcing bars including inelastic buckling and low-cycle fatigue degradation. Comput Struct 156:58-71

Kashani MM, Lowes LN, Crewe AJ, Alexander NA (2016) Nonlinear fibre element modelling of RC bridge piers considering inelastic buckling of reinforcement. Eng Struct 116:163-177

Kashani MM, Málaga-Chuquitaype C, Yang S, Alexander NA (2017a) Influence of non-stationary content of ground-motions on nonlinear dynamic response of RC bridge piers. Bull Earthq Eng 15(9):3897-3918

Kashani MM, Salami MR, Goda K, Alexander NA (2017b) Nonlinear flexural behaviour of RC columns including bar buckling and fatigue degradation. Mag Concr Res 70(5):231-247

Kempton JJ, Stewart JP (2006) Prediction equations for significant duration of earthquake ground-motions considering site and near-source effects. Earthq Spectra 22(4):985-1013

Kramer SL (1996) Geotechnical earthquake engineering, vol 80. Prentice Hall, Upper Saddle River

Kunnath SK, El-Bahy A, Taylor AW, Stone WC (1997) Cumulative seismic damage of reinforced concrete bridge piers. Technical Report NCEER

Kwan WP, Billington SL (2003) Influence of hysteretic behavior on equivalent period and damping of structural systems. J Struct Eng 129(5):576-585

Laplace PN, Sanders D, Saiidi MS, Douglas B (1999) Shake table testing of flexure dominated reinforced concrete bridge columns. Doctoral dissertation, University of Nevada Reno, Reno, Nevada

Lee WK, Billington SL (2009) Modeling residual displacements of concrete bridge columns under earthquake loads using fiber elements. J Bridge Eng 15(3):240-249

Lehman DE (2000) Seismic performance of well-confined concrete bridge columns. Pacific Earthquake Engineering Research Centre, Berkeley

Mander JB, Priestley MJN, Park R (1988) Theoretical stress-strain model for confined concrete. J Struct Eng 114(8): $1804-1825$

MATLAB, R2016b (1994-2017) The MathWorks lnc. www.mathworks.com. Accessed April 2017

Nojavan A, Schultz AE, Chao SH (2017) Analytical study of in-plane buckling of longitudinal bars in reinforced concrete columns under extreme earthquake loading. Eng Struct 134:48-60

Phan V, Saiidi MS, Anderson J, Ghasemi H (2007) Near-fault ground-motion effects on reinforced concrete bridge columns. J Struct Eng 133(7):982-989

Raghunandan M, Liel AB (2013) Effect of ground-motion duration on earthquake-induced structural collapse. Struct Saf 41:119-133

Salami MR, Kashani MM, Goda K (2019) Influence of advanced structural modeling technique, mainshockaftershock sequences, and ground-motion types on seismic fragility of low-rise RC structures. Soil Dyn Earthq Eng 117:263-279

Sarieddine M, Lin L (2013) Investigation correlations between strong-motion duration and structural damage. Structures congress: bridging your passion with your profession. Pittsburgh, Pennsylvania. American Society of Civil Engineers, Reston, pp 2926-2936

Semmlow JL, Griffel B (2009) Biosignal and medical image processing, 2nd edn. CRC Press, Cambridge

Stanton J, McNiven H (1979) The development of a mathematical model to predict the flexural response of reinforced concrete beams to cyclic loads, using system identification. Rep. No. EERC 79-02, Earthquake Engineering Research Center, University of California, Berkeley, California

Su J, Dhakal RP, Wang J (2017) Fiber-based damage analysis of reinforced concrete bridge piers. Soil Dyn Earthq Eng 96:13-34

Vold H, Crowley J, Rocklin GT (1984) New ways of estimating frequency response functions. Sound Vib 18(11):34-38

Welch PD (1967) The use of fast fourier transform for the estimation of power spectra a method based on time averaging over short, modified periodograms. IEEE Trans Audio Electroacoust 15(2):70-73

Publisher's Note Springer Nature remains neutral with regard to jurisdictional claims in published maps and institutional affiliations. 